\title{
Education in Moroccan Long-Term Childhood Cancer Survivors
}

Nadia Benaicha ${ }^{1}$, Fouzia Msefer Alaoui ${ }^{2}$, Karima Elrhazi $^{1}$, Oussmane Desire Diakite ${ }^{1}$, Oussmane Sy $^{1}$ and Chakib Nejjari ${ }^{1}$

1. Department of Epidemiology and Clinical Research, Faculty of Medicine, Fez-30000, Morocco

2. Department of Oncology of Children Hospital of Rabat. The Avenir, Parents and Friends of Children with Cancer Association,

Rabat-10000, Morocco

\begin{abstract}
In developed countries, currently more than $80 \%$ of children with cancer survive and they are considered as cured. However, the survivors are at high risk of medical and social late effects. In Morocco, childhood cancer accounts for $3 \%$ of all cancers. The purpose of this study was to look for factors related to education in Moroccan childhood cancer survivors. This was a cross-sectional study conducted among childhood cancer survivors treated between 1978 and 2004 at the Pediatric Oncology Unit of Children's Hospital of Rabat. Medical and demographic data were collected through questionnaires completed by phone or internet, by the survivor, his parent or his physician. Among 995 patients considered cured, only 195 were found. The decline from the initial diagnosis varies from 10 years to 36 years, with a mean of 16.2 years and a standard deviation of 6.3 years. Educated survivors are more likely to live with their partner $(P<0.0001)$, and most of them are students $(P<0.0001)$. They have less cognitive problems than the not educated $(P<0.0001)$. To our knowledge, there is no previous study about the fate of Moroccan childhood cancer survivors before our study. Hence, it was a cross-sectional study to have a quick picture on the situation in Morocco. This survey revealed that Moroccan survivors didn't suffer from education problems. Actually, most of them continued their education during or after their treatment.
\end{abstract}

Key words: Childhood, cancer, survivors, education, Morocco.

\section{Introduction}

Children's malignant tumors are major causes of death in children under 15 years old in the West [1]. According to data from literature, childhood cancers are dominated by leukemia, tumors of the central nervous system (CNS) tumors of the bone and soft tissue [2]. Young people cured of childhood cancer may develop complications related to the disease itself or the treatment. With advances in cancer treatment, today more than $80 \%$ of children diagnosed with cancer in developed countries are alive at least five years after diagnosis. Many ultimately will be considered cured [2]. Surgery, chemotherapy, and radiation are associated with late health effects that can affect survivors' physical, psychosocial and

Corresponding author: Nadia Benaicha, M.D., research field: childhood cancer survivors. cognitive functioning [3-6]. Many survivors report education difficulties, and hence unemployment, and lower incomes in comparison with siblings populations [7-11]. The impact of childhood Moroccan childhood cancer survivors on occupational achievement, however, has not been reported yet to our knowledge.

The North American Childhood Cancer Survivor Study (CCSS) showed reduced education attainment level and diminished cognitive functioning encompassing memory, quantitative skills, and abstract reasoning have been well documented in selected groups of survivors of childhood cancer. Deficits have been seen most often in children with acute leukemia or CNS tumors who received cranial radiation and/or intrathecal therapy. The subgroup of survivors who received special education services was found to have 
high school graduation rates similar to those of the sibling cohort, with the only exception being survivors of CNS cancers and Wilms tumor. Although a high proportion of childhood cancer survivors will successfully complete high school, the results of this CCSS analysis provides support for closely monitoring survivors and for early identification of signs of learning disabilities so that special education intervention can be planned [12].

The objective of the study was to establish a long term follow up of survivors and identify medical and social disorders. The aim of this present survey was to describe education in childhood cancer survivors treated at pediatric oncology unit of the University Children Hospital of Rabat between 1978 and 2004 in order to evaluate late effects on their social, economic and demographic outcomes.

\section{Materials and Methods}

\subsection{Type of Study}

This was a full coverage descriptive cross-sectional study.

\subsection{Study Population}

The study population consists of young people cured from childhood cancer ( 0 to 15 years) treated in Pediatric Oncology Unit of the Children Hospital of Rabat between 1978 and 2004. These young people were CR1 (complete remission without relapse) CR2 (complete remission after a single relapse) and CR3 (complete remission after 2 relapses).

This study has been presented to the local ethics committee of University Hospital Hassan II of Fez who agreed it. Informed consent has been sent to every potential participant. Questionnaires, upon receipt, have been assigned a unique number and at any time during the analysis of the study no person had been cited. These points were clearly stated in the informed consent so that the survivor of childhood cancer was not reluctant to give confidential information.

\subsection{Data Collection}

Initial and current medical and demographic data were collected through questionnaires completed by phone or internet by the survivor himself, his parent or his physician. Each subject enrolled in the study was contacted by phone or internet in order to present the purpose of the investigation and explain the necessity of participation of each subject. The revival was made for subjects who did not respond by telephone using social networks (facebook ...).

\subsection{Statistical Analysis}

All variables were summarized by using descriptive statistics. Categorical variables were described in terms of proportions and quantitative variables were described in terms of average extreme values and standard deviation.

The association between dependent variable (education level) and several potential explanatory variables was investigated. Bi-variate analysis was used and the association between two categorical variables (for example education level and sex) was searched by chi-square test, and was selected as the significance level a $P$ value of 0.05 . Statistical analysis was done on SPSS Version 17

\section{Results}

Among 995 patients considered cured by their last news, only 195 were found. Five (5) deaths from second malignancy or late relapse were included in our database.

\subsection{Descriptive Data}

The decline from the initial diagnosis varies from 10 years to 36 years, with a mean (an average) of 16.2 years and a standard deviation of 6.3 years. The male was dominant with Sex Ratio of 1.7. The range of ages of children varies from 1 month to 16 years, with a mean of 6.2 years and a standard deviation of 3.9 years. Ages 0-9 years were the most represented, totaling $77.8 \%$. More than $50 \%$ of the survivors 
completing questionnaires were diagnosed and treated during the period from 2000 to 2004 and $75 \%$ from 1995 to 2004 . The majority of our study population lived in urban areas (77\%).

The majority of the survivors had acute lymphoblastic leukemia (ALL) (26.4\%), No Hodgkinien Lymphoma (23.6\%), Hodgkin Disease (14.8\%) and nephroblastoma (14.8\%). Almost all of the patients received chemotherapy, one third was operated on and one third irradiated. The vast majority of survivors never relapsed.

The majority of the participants were aged more than 18 years old (71.6\%) and 31 were married $(16.1 \%$ of adults). They were aged between 23 and 43 (the mean was 31.8 and the SD is 5.9). 19 (61.3\%) were employed and 9 (37.5\%) makes sports (at least 3 hours per week) (Table 1).

\subsection{Correlations Education/Other Variables}

Educated survivors are more likely to live with their partner $(P<0.0001)$, and most of them are students $(P$ $<$ 0.0001). We didn't find relation statistically significant between education level and $\operatorname{sex}(P=0.810)$. No correlations have been found with education level and sport practice (Table 2).

Educated survivors have less cognitive problems than the not educated $(P<0.0001)$. We didn't find relation statically significant between education level and aesthetic problems, or psychological problems. We found a $P$ value close to significance between education level and addiction (0.059) (Table 3).

With the question of health subjective evaluation, we didn't find a relation statistically significant with education level $(P=0.315)$ (Table 4$)$.

Table 1 Descriptive data among 195 Moroccan childhood cancer survivors treated between 1978 and 2004.

\begin{tabular}{|c|c|c|c|}
\hline & & Frequency & Percentage $(\%)$ \\
\hline \multirow{2}{*}{$\operatorname{Sex}(n=190)$} & Female & 69 & 36.3 \\
\hline & Male & 121 & 63.7 \\
\hline \multirow{5}{*}{ Education } & Not educated & 1 & 0.6 \\
\hline & Primary School & 21 & 12.0 \\
\hline & Middle School & 56 & 32.0 \\
\hline & High School & 34 & 19.4 \\
\hline & College/University & 63 & 36.0 \\
\hline \multirow{2}{*}{ Adult $(\geq 18$ years old $)(n=194)$} & Yes & 139 & 71.6 \\
\hline & No & 55 & 28.4 \\
\hline \multirow{2}{*}{ Marital status $(n=139)$} & Ever Married & 31 & 22.3 \\
\hline & Not married & 108 & 77.7 \\
\hline \multirow{4}{*}{ Age at diagnosis in years $(n=189)$} & $00-04$ & 81 & 42.9 \\
\hline & 05-09 & 66 & 34.9 \\
\hline & $10-15$ & 39 & 20.6 \\
\hline & $15-19$ & 3 & 1.6 \\
\hline \multirow{5}{*}{ Years of diagnosis $(n=185)$} & 1978-1984 & 7 & 3.8 \\
\hline & 1984-1989 & 19 & 10.3 \\
\hline & 1990-1994 & 20 & 10.8 \\
\hline & 1995-1999 & 33 & 17.8 \\
\hline & 2000-2004 & 106 & 57.3 \\
\hline \multirow{2}{*}{ Origin at diagnosis $(n=183)$} & Urban & 142 & 77.6 \\
\hline & Rural & 41 & 22.4 \\
\hline \multirow{3}{*}{ Evolution } & CRR & 148 & 93.0 \\
\hline & $\mathrm{CR} 2$ & 9 & 5.7 \\
\hline & CR3 & 2 & 1.3 \\
\hline
\end{tabular}


Table 2 Comparison of education level with $t$ socio-demographic data among 195 Moroccan childhood cancer survivors treated between 1978 and 2004.

\begin{tabular}{|c|c|c|c|c|c|c|c|}
\hline & & Not educated & Primary school & Middle school & High school & College/university & $P$ value \\
\hline \multirow{2}{*}{$\operatorname{Sex}(n=173)$} & Female & $0(0.0 \%)$ & $7(33.3 \%)$ & $22(39.3 \%)$ & $11(32.4 \%)$ & $26(41.3 \%)$ & \multirow{2}{*}{0.810} \\
\hline & Male & $1(100.0 \%)$ & $14(66.7 \%)$ & $34(60.7 \%)$ & $23(67.6 \%)$ & $37(58.7 \%)$ & \\
\hline \multirow{4}{*}{$\begin{array}{l}\text { Age initial at diagnosis } \\
(n=174)\end{array}$} & $00-04$ & $1(100.0 \%)$ & $13(61.9 \%)$ & $32(57.1 \%)$ & $15(44.1 \%)$ & $17(27.4 \%)$ & \multirow{4}{*}{0.029} \\
\hline & $05-09$ & $0(0.0 \%)$ & $5(23.8 \%)$ & $18(32.1 \%)$ & $14(41.2 \%)$ & $24(38.7 \%)$ & \\
\hline & $10-14$ & $0(0.0 \%)$ & $2(9.5 \%)$ & $6(10.7 \%)$ & $5(14.7 \%)$ & $20(32.3 \%)$ & \\
\hline & $15-19$ & $0(0.0 \%)$ & $1(4.8 \%)$ & $0(0.0 \%)$ & $0(0.0 \%)$ & $1(1.6 \%)$ & \\
\hline \multirow{3}{*}{ Habitat type $(n=163)$} & With parents & $0(0.0 \%)$ & $17(85.0 \%)$ & $44(89.8 \%)$ & $27(84.4 \%)$ & $35(57.4 \%)$ & \multirow{3}{*}{0.000} \\
\hline & Alone & $0(0.0 \%)$ & $0(0.0 \%)$ & $0(0.0 \%)$ & $2(6.2 \%)$ & $13(21.3 \%)$ & \\
\hline & With partner & $1(100.0 \%)$ & $3(15.0 \%)$ & $5(10.2 \%)$ & $3(9.4 \%)$ & $13(21.3 \%)$ & \\
\hline \multirow{3}{*}{$\begin{array}{l}\text { Working status } \\
(n=70)\end{array}$} & Employed & $0(0.0 \%)$ & $8(40.0 \%)$ & $16(29.6 \%)$ & $6(18.8 \%)$ & $1(1.6 \%)$ & \multirow{3}{*}{0.000} \\
\hline & Unemployed & $1(100.0 \%)$ & $4(20.0 \%)$ & $6(11.1 \%)$ & $5(15.6 \%)$ & $30(47.6 \%)$ & \\
\hline & Student & $0(0.0 \%)$ & $8(40.0 \%)$ & $32(59.3 \%)$ & $21(65.6 \%)$ & $32(50.8 \%)$ & \\
\hline \multirow{2}{*}{$\begin{array}{l}\text { Makes sport (at least } 3 \\
\text { hours per week) }(n= \\
43)\end{array}$} & Yes & $1(100.0 \%)$ & $11(61.1 \%)$ & $26(55.3 \%)$ & $16(66.7 \%)$ & $31(58.5 \%)$ & \multirow{2}{*}{0.813} \\
\hline & No & $0(0.0 \%)$ & $7(38.9 \%)$ & $21(44.7 \%)$ & $8(33.3 \%)$ & $22(41.5 \%)$ & \\
\hline
\end{tabular}

Table 3 Comparison of marital status with current medical data among 195 Moroccan childhood cancer survivors treated between 1978 and 2004.

\begin{tabular}{|c|c|c|c|c|c|c|c|}
\hline & & Not educated & Primary school & Middle school & High school & College/university & $P$ value \\
\hline \multirow{2}{*}{ Physical Problems $(n=172)$} & Yes & $1(100.0 \%)$ & $6(28.6 \%)$ & $17(30.4 \%)$ & $14(42.5 \%)$ & $22(36.1 \%)$ & \multirow{2}{*}{0.462} \\
\hline & No & $0(0.0 \%)$ & $15(71.4 \%)$ & $39(69.6 \%)$ & $19(57.6 \%)$ & $39(63.9 \%)$ & \\
\hline \multirow{2}{*}{ Aesthetic Problems $(n=157)$} & Yes & $0(0.0 \%)$ & $3(15.8 \%)$ & $9(18.4 \%)$ & $3(9.7 \%)$ & $9(15.8 \%)$ & \multirow{2}{*}{0.862} \\
\hline & No & $1(100.0 \%)$ & $16(84.2 \%)$ & $40(81.6 \%)$ & $28(90.3 \%)$ & $48(84.2 \%)$ & \\
\hline \multirow{2}{*}{ Psychical Problems $(n=171)$} & Yes & $0(0.0 \%)$ & $6(28.6 \%)$ & $8(14.3 \%)$ & $9(27.3 \%)$ & $11(18.3 \%)$ & \multirow{2}{*}{0.468} \\
\hline & No & $1(100.0 \%)$ & $15(71.4 \%)$ & $48(85.7 \%)$ & $24(72.7 \%)$ & $49(81.7 \%)$ & \\
\hline \multirow{2}{*}{ Cognitive Problems $(n=172)$} & Yes & $2(100.0 \%)$ & $19(95.0 \%)$ & $2(3.6 \%)$ & $1(2.9 \%)$ & $0(0.0 \%)$ & \multirow{2}{*}{0.000} \\
\hline & No & $0(0.0 \%)$ & $1(5.0 \%)$ & $53(96.4 \%)$ & $33(97.1 \%)$ & $61(100.0 \%)$ & \\
\hline \multirow{2}{*}{ Addiction $(n=170)$} & Yes & $55(91.7 \%)$ & $17(85.0 \%)$ & $1(1.6 \%)$ & $1(3.0 \%)$ & $5(8.3 \%)$ & \multirow{2}{*}{0.059} \\
\hline & No & $5(8.3 \%)$ & $3(15.0 \%)$ & $55(98.4 \%)$ & $32(97.0 \%)$ & $55(91.7 \%)$ & \\
\hline
\end{tabular}

Table 4 Comparison of education level with subjective health evaluation among 195 Moroccan childhood cancer survivors treated between 1978 and 2004.

\begin{tabular}{lllllll}
\hline & Not educated & Primary school & Middle school & High school & College/university & $P$ value \\
\hline Very good $(n=55)$ & $1(100.0 \%)$ & $6(28.6 \%)$ & $11(19.6 \%)$ & $16(47.1 \%)$ & $21(33.3 \%)$ & \\
Good $(n=45)$ & $0(0.0 \%)$ & $6(28.6 \%)$ & $19(33.9 \%)$ & $3(8.8 \%)$ & $17(27.9 \%)$ & 0.315 \\
Average $(n=35)$ & $0(0.0 \%)$ & $6(28.6 \%)$ & $12(21.4 \%)$ & $7(20.6 \%)$ & $10(15.9 \%)$ & $1(1.6 \%)$ \\
Bad $(n=8)$ & $0(0.0 \%)$ & $2(9.5 \%)$ & $4(7.1 \%)$ & $1(2.9 \%)$ & $0(0.0 \%)$ & $1(1.6 \%)$ \\
Very bad $(n=3)$ & $0(0.0 \%)$ & $0(0.0 \%)$ & $2(3.6 \%)$ & 0 & \\
\hline
\end{tabular}

\section{Discussion}

To our knowledge, there is no previous study about the fate of Moroccan childhood cancer survivors before our study. In Morocco, treatment of childhood cancer is dominated by curative treatment. Hence, it was a cross-sectional study to have a quick picture on the situation in Morocco. The study had to be exhaustive, but only 195 among 995 were found. The survivors were diagnosed between 1978 and 2004 and the survey was made on 2014, which means that we have decline from 34 to 10 years. Consequently, many of them have changed their coordinates. Furthermore, the questionnaire was elaborated to fill by the patients themselves, but some questionnaires were filled from medical records or by some participant's close 
relatives. However, retrieved data are interesting, and require reflection on many levels.

Educational difficulties among survivors have been reported by many survivors, parents and teachers [13-15]. Survivors attain lower levels of education [16-19]. In our study, we found that Moroccan childhood cancer survivors didn't suffer from education exclusion. Actually, more than half of them (55.4\%) have high school or university level. In comparison with siblings, our study population had better education level as in Moroccan general population about $40 \%$ is not educated [20]. One possible explanation is that childhood cancer can be a motivation for the children and their families to continue their education.

Many studies had reported sex differences among survivors education level, actually girls appears to be less educated than boys [21-23]. In our study, we didn't find a difference statistically significant between girls and boys.

In this study, we found that young age at diagnosis is a risk factor of low level of education $(P=0.029)$. Educated survivors are more likely to be employed ( $P$ $<0.0001)$ and so to have enough money to live alone or with their partner $(P<0.0001)$.

Cognitive problems are risk factor of low education level $(P<0.0001)$, the association between addiction and education level were close to significance $(P=$ $0.059)$, it can be considered as risk factor of low level of education. Maybe if we increase the power of the study by including other survivors, we can have significant association.

\section{Conclusion}

The childhood cancer survivors are increasing in developed countries, but also in developing countries. However, they stay at risk of late medical and demographic issues. This survey revealed that Moroccan survivors didn't suffer from education problems. Actually, most of them continued their education during or after their treatment.
This follow-up should provide medical care also psychosocial and educational support for patients and their families.

\subsection{What Is Already Know on This Topic}

Children's malignant tumors are major causes of death in children under 15 years old. Young people cured of childhood cancer may develop complications related to the disease itself or the treatment. Many survivors report education difficulties, and hence unemployment, and lower incomes in comparison with siblings populations.

\subsection{What This Study Adds}

To our knowledge, there is no previous study about the fate of Moroccan childhood cancer survivors before our study. This survey revealed that Moroccan survivors didn't suffer from education problems.

\section{Acknowledgement}

Thanks to the team of Epidemiology of the University Hospital of $\mathrm{Fez}$, the team of Pediatric Hematology-Oncology Service of the University Children Hospital of Rabat, the Embassy of Canada Morocco, the Avenir association, the Women, Values and Realizations Association, and the Terry Fox Foundation.

Thanks to the survivors who accepted to answer questions, and to their families.

\section{References}

[1] National Institute of Cancer. 2013. "Childhood Cancer: Complications and Sequel." Accessed March 30, 2013. http://www.e-cancer.fr/cancerinfo/les-cancers/le-cancer-c hez-1-enfant/complications-tardives-et-sequelles-eventuel les (in French)

[2] National Institute of Health. 2015. "Childhood Cancer Survivor Study: An Overview.” Accessed April 21, 2015. http://www.cancer.gov/types/childhood-cancers/ccss.

[3] Ness, K. K., Hudson, M. M., Ginsberg, J. P., Nagarajan, R., Kaste, S. C., Marina, N., Whitton, J., Robison, L. L., and Gurney, J. G. 2009. "Physical Performance Limitations in the Childhood Cancer Survivor Study Cohort." J. Clin. Oncol. 27 (14): 2382-9. 
[4] James, G. G., Kevin, R. K., Nina, K. H., Stacy, N., Paul, C. N., Brad, Z., Jean, M. T., and Kirsten, K. N. 2009. "Social Outcomes in the Childhood Cancer Survivor Study Cohort." J. Clin. Oncol. 27 (14): 2390-5.

[5] Ellenberg, L., Liu, Q., Gioia, G., Yasui, Y., Packer, R. J., Mertens, A., Donaldson, S. S., Stovall, M., Kadan-Lottick, N., Armstrong, G., Robison, L. L., and Zeltzer, L. K. 2009. "Neurocognitive Status in Long-Term Survivors of Childhood CNS Malignancies: A Report from the Childhood Cancer Survivor Study." Neuropsychology 23 (6): 705-17.

[6] Kadan-Lottick, N. S., Zeltzer, L. K., Liu, Q., Yasui, Y., Ellenberg, L., Gioia, G., Robison, L. L., and Krull, K. R. 2010. "Neurocognitive Functioning in Adult Survivors of Childhood non-Central Nervous System Cancers." J. Natl. Cancer Inst. 102 (12): 881-93.

[7] Mitby, P. A., Robison, L. L., Whitton, J. A., Zevon, M. A., Gibbs, I. C., Tersak, J. M., Meadows, A. T., Stovall, M., Zeltzer, L. K., Mertens, A. C., and Childhood Cancer Survivor Study Steering Committee. 2003. "Utilization of Special Education Services and Educational Attainment among Long-Term Survivors of Childhood Cancer: A Report from the Childhood Cancer Survivor Study." Cancer 97 (4): 1115-26.

[8] de Boer, A. G., Verbeek, J. H., and van Dijk, F. J. 2006. "Adult Survivors of Childhood Cancer and Unemployment: A Meta Analysis.” Cancer 107 (1): 1-11.

[9] Crom, D. B., Lensing, S. Y., Rai, S. N., Snider, M. A., Cash, D. K., and Hudson, M. M. 2007. "Marriage, Employment, and Health Insurance in Adult Survivors of Childhood Cancer." J. Cancer Surviv. 1 (3): 237-45.

[10] Park, E. R., Li, F. P., Liu, Y., Emmons, K. M., Ablin, A., Robison, L. L., Mertens, A. C., and Childhood Cancer Survivor Study. 2005. "Health Insurance Coverage in Survivors of Childhood Cancer: The Childhood Cancer Survivor Study." J. Clin. Oncol. 23 (36): 9187-97.

[11] Barrera, M., Shaw, A. K., Speechley, K. N., Maunsell, E., and Pogany, L. 2005. "Educational and Social Late Effects of Childhood Cancer and Related Clinical, Personal, and Familial Characteristics." Cancer 104 (8): 1751-60.

[12] Armstrong, G. T., Liu, Q., Yasui, Y., Huang, S., Ness, K. K., Leisenring, W., Hudson, M. M., Donaldson, S. S., King, A. A., Stovall, M., Krull, K. R., Robison, L. L., and Packer, R. J. 2009. "Long-Term Outcomes among Adult Survivors of Childhood Central Nervous System Malignancies in the Childhood Cancer Survivor Study." J. Natl. Cancer Inst. 101 (13): 946-58.

[13] Dolgin, M. J., Somer, E., Buchvald, E., and Zaizov, R. 1999. "Quality of Life in Adult Survivors of Childhood Cancer." Soc. Work Health Care. 28 (4): 31-43.

[14] Jannoun, L., and Chessells, J. M. 1987. "Long-Term
Psychological Effects of Childhood Leukemia and Its Treatment." Pediatr. Hematol. Oncol. 4 (4): 293-308.

[15] Raymond-Speden, E., Tripp, G., Lawrence, B., and Holdaway, D. 2000. "Intellectual, Neuropsychological, and Academic Functioning in Long-term Survivors of Leukemia." J. Pediatr. Psychol. 25 (2): 59-68.

[16] Koch, S. V., Kejs, A. M. T., Engholm, G., Johansen, C., and Schmiegelow, K. 2004. "Educational Attainment among Survivors of Childhood Cancer: A Population-Based Cohort Study in Denmark." $\mathrm{Br}$. J. Cancer 91 (5): 923-8.

[17] Nagarajan, R., Neglia, J. P., Clohisy, D. R., Yasui, Y., Greenberg, M., Hudson, M., Zevon, M. A., Tersak, J. M., Ablin, A., and Robison, L. L. 2003. "Education, Employment, Insurance, and Marital Status among 694 Survivors of Pediatric Lower Extremity Bone Tumors: A Report from the Childhood Cancer Survivor Study." Cancer 97 (10): 2554-64.

[18] Link, K., Moëll, C., Osterberg, K., Persson, R., Ørbaek, P., Garwicz, S., Cavallin-Ståhl, E., and Erfurth, E. M. 2006. "Adult Survivors of Childhood Acute Lymphoblastic Leukaemia with GH Deficiency Have Normal Self-Rated Quality of Life but Impaired Neuropsychological Performance 20 Years after Cranial Irradiation." Clin. Endocrinol. (Oxf). 65 (5): 617-25.

[19] Zebrack, B. J., Zevon, M. A., Turk, N., Nagarajan, R., Whitton, J., Robison, L. L., and Zeltzer, L. K. 2007. "Psychological Distress in Long-Term Survivors of Solid Tumors Diagnosed in Childhood: A Report from the Childhood Cancer Survivor Study." Pediatr. Blood Cancer 49 (1): 47-51.

[20] High Commissioner for Planning. 2015. Morocco in Numbers. Accessed July 1, 2015. http://www.hcp.ma/downloads/Maroc-en-chiffres_t13053 .html (in French)

[21] Langeveld, N. E., Ubbink, M. C., Last, B. F., Grootenhuis, M. A., Voute, P. A., and De Haan, R. J. 2003. "Educational Achievement, Employment and Living Situation in Long-Term Young Adult Survivors of Childhood Cancer in the Netherlands." Psychooncology 12 (3): 213-25.

[22] Kelaghan, J., Myers, M. H., Mulvihill, J. J., Byrne, J., Connelly, R. R., Austin, D. F., Strong, L. C., Meigs, J. W., Latourette, H. B., and Holmes, G. F. 1988. "Educational Achievement of Long-Term Survivors of Childhood and Adolescent Cancer." Med. Pediatr. Oncol. 16 (5): 320-6.

[23] Haupt, R., Fears, T. R., Robison, L. L., Mills, J. L., Nicholson, H. S., Zeltzer, L. K., Meadows, A. T., and Byrne, J. 1994. "Educational Attainment in Long-Term Survivors of Childhood Acute Lymphoblastic Leukemia." JAMA 272 (18): 1427-32. 